\title{
ANALYSIS AND COMPARISION OF SRG AND DFIG FOR WIND GENERATION APPLICATION \\ K.PRATHAP ${ }^{1}$, Dr.N.C.LENIN ${ }^{2}$
}

\author{
${ }^{1}$ Student, M.E. Power Systems, St. Joseph's College of Engineering, Chennai, Tamil Nadu, India \\ ${ }^{2}$ Associate Professor, School of Electrical, VIT University, Chennai Campus, Chennai, Tamil Nadu, India \\ nclenin@ieee.org
}

\begin{abstract}
Renewable energy is very important topic to be study to find new sources of energy to produce electricity. The main advantages of the renewable energy are available, clean, low cost, and continuous energy.

The main objective of this paper is to document the comparative and absolute advantages and disadvantages of using Switched Reluctance Generator (SRG's) and Doubly Fed Induction Generator (DFIG's) in wind generation. The comparative study is based on the machine parameters like inductance, flux linkage, torque, output power, weight and cost. Performance analysis has been carried out using Finite Element Analysis (FEA). The predicted results show SRG'S has the optimal choice for Wind Generation.
\end{abstract}

\section{INTRODUCTION}

Wind powered generators must operate efficiently under variable speed conditions. Although the efforts are getting it from conventional machines, a devoted special machine is welcome. The switched reluctance machine represent one of the simplest types of electrical machines and Switched Reluctance Generator. SRG is a potential device for variable speed power generation. Investigation conducted to explore this new potion showed that it is promising due to the new advances in power electronics and in micro processing. The SRG is reliable efficient and present some specific characteristics that match the needs of wind power.

The induction generator is the most common generator in wind energy application due to its simplicity and ruggedness. More than 50 years life time, the same machine is used as motor or generator without modification, high power per unit mass of materials and flexibility in speed range of operation. The main drawbacks in induction machine are its lower efficiency and the need for reactive power to build up the terminal voltage. However the efficiency can be improved by modern design and the solid state converters can be used to supply reactive power required.

Induction generator has a widely acceptance in using with wind energy conversion for many reasons. Induction generator is very simple, reliable, cheap, light weight, long life time, produces high power per unit mass of materials and requires very less maintenance. Also, induction generator works with constant speed constant frequency system as well as variable speed constant frequency system.

\section{DOUBLY FED INDUCTION GENERATOR}

The induction generator is the most common generator in wind energy application due to its simplicity and ruggedness. More than 50 years life time, the same machine is used as motor or generator without modification, high power per unit mass of materials and flexibility in speed range of operation. The main drawbacks in induction machine are its lower efficiency and the need for reactive power to build up the terminal voltage. However the efficiency can be improved by modern design and the solid state converters can be used to supply reactive power required.

Induction generator has a widely acceptance in using with wind energy conversion for many reasons. Induction generator is very simple, reliable, cheap, light weight, long life time, produces high power per unit mass of materials and requires very less maintenance. Also, induction generator works with constant speed constant frequency system as well as variable speed constant frequency systems.

The induction motor can also run as a generator. This simply happens when you, instead of forcing the rotor to turn at a rotational speed lower than the synchronous speed, exceed this synchronous speed by applying an outside energy source, such as diesel motor or a set of wind turbine rotor blades. Once again, the greater the difference between the rotating magnetic field of the stator and the speed of the rotor, the greater the torque produced by the rotor. When it is working as a generator, the rotating field however acts as a brake in slowing the rotor. The stator experiences a variable magnetic field from the rotor that drags its rotting magnetic field and thereby induces an electrical current in the stator. In comparison to motor operation the induced currents in the rotor and the stator will flow in the opposite direction, which means that power will be sent to the grid. The faster the rotor turns in relation to the magnetic field of the stator, the greater induction in the stator and the greater the production of power.

\subsection{ANALYTICAL FORMULAS}

Output Equation

$$
\mathrm{KVA} \text { input } \mathrm{Q}=\mathrm{C}_{\mathrm{O}} \mathrm{D}^{2} \mathrm{Ln}
$$

Output co-eff $\mathrm{C}_{\mathrm{O}}=1.1 \mathrm{k}_{\mathrm{w}} \mathrm{B}_{\mathrm{av}} \mathrm{ac} * 10^{-3}$

$$
\begin{aligned}
& \mathrm{D}=\text { core length } \\
& \mathrm{L}=\text { pole pitch }
\end{aligned}
$$


Council for Innovative Research www.cirworld.com
International Journal of Computers \& Technology Volume 4 No. 2, March-April, 2013, ISSN 2277-3061

Flux per Pole

$$
\phi_{m}=B_{a v} \tau L=B_{a v} *(\pi D L) / p
$$

Stator voltage per phase

$$
E_{s}=4.44 f \phi_{m} T_{s} K_{w s}
$$

$\mathrm{T}_{\mathrm{s}}=$ no of turns per phase

$\mathrm{K}_{\mathrm{ws}}=$ stator winding factor

Stator turns per phase

$$
T_{s}=\frac{E_{s}}{4.44 f \phi_{m} K_{w s}}
$$

$$
f=\text { frequency }
$$

Stator conductors

Stator current per phase

$$
I_{s}=\frac{Q}{2 F} a m p
$$

Area of each sedtor conductor

$\alpha_{s}=I_{s} \delta_{s}$

$\delta_{s}=$ current density in stator conductor

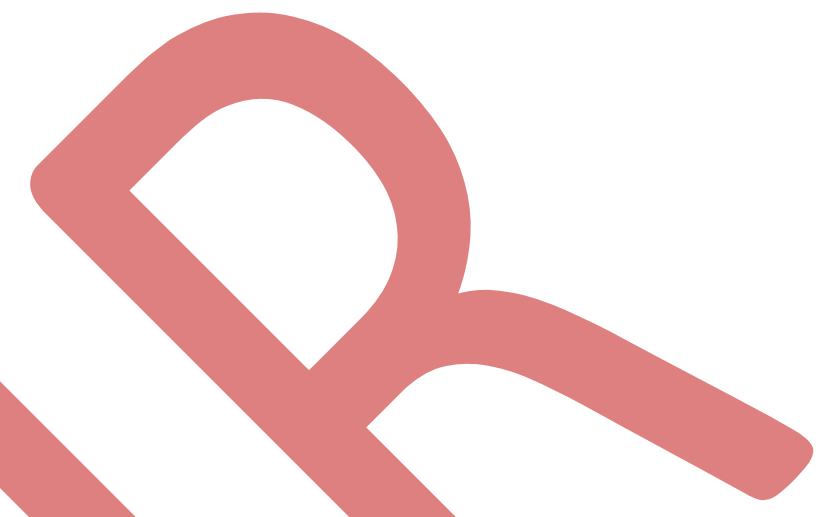

Stator slot pitch

$\delta_{s}=$
$\mathrm{I}_{\mathrm{s}}=$ stator currrent

$Y_{s g}=$ gap surface / total no slots

$$
=\frac{\pi D}{S_{g}}
$$

$S_{g}=$ no of stator conductor

Area of each slot $=$ copper area per slot/space factor

Length of mean space

$$
=\frac{Z_{s g} * \alpha_{g}}{\text { spacefactor }}
$$

$$
\begin{gathered}
L m t s=2 L+2.3 \tau+0.24 \\
L \& \quad \text { Expressed in } m
\end{gathered}
$$

Stator teeth

$$
\begin{aligned}
& \begin{array}{l}
\text { min tooth area per pole } \\
\text { min width of stator tooth }
\end{array} \\
& W_{t s \text { min }}=\frac{\phi_{m}}{\mathbf{1 . 7}} \\
& \text { area of stator core }=\frac{\phi_{m}}{2 B_{c s}} \\
& \text { Outside diameter }
\end{aligned}
$$$$
D_{0}=\mathrm{D}+2 \text { (depth of stator slot }+ \text { depth of core)mm }
$$$$
D_{0}=D+2 d_{s s}+2 d_{s s}
$$

\subsection{ANALYTICAL RESULT}


Council for Innovative Research www.cirworld.com
International Journal of Computers \& Technology Volume 4 No. 2, March-April, 2013, ISSN 2277-3061

ROTOR DIAMETER

TORQUE

$$
\begin{aligned}
& D_{o}=2 * r \\
& r=\frac{157}{2 * \pi}=25
\end{aligned}
$$

$D_{o}=2 * 25=50 \mathrm{~mm}$

SLIP RING

$$
\begin{aligned}
& \tau=\frac{P_{\text {gap }}}{\omega_{s}} \\
& P_{\text {gap }}=233.326 \\
& \omega_{s}=\frac{4 \pi f_{e}}{3 P_{3}}=\frac{4 * \pi * 50}{1}=628.31 \\
& \tau=\frac{233.326}{62.831}=3.71 \mathrm{~nm}
\end{aligned}
$$

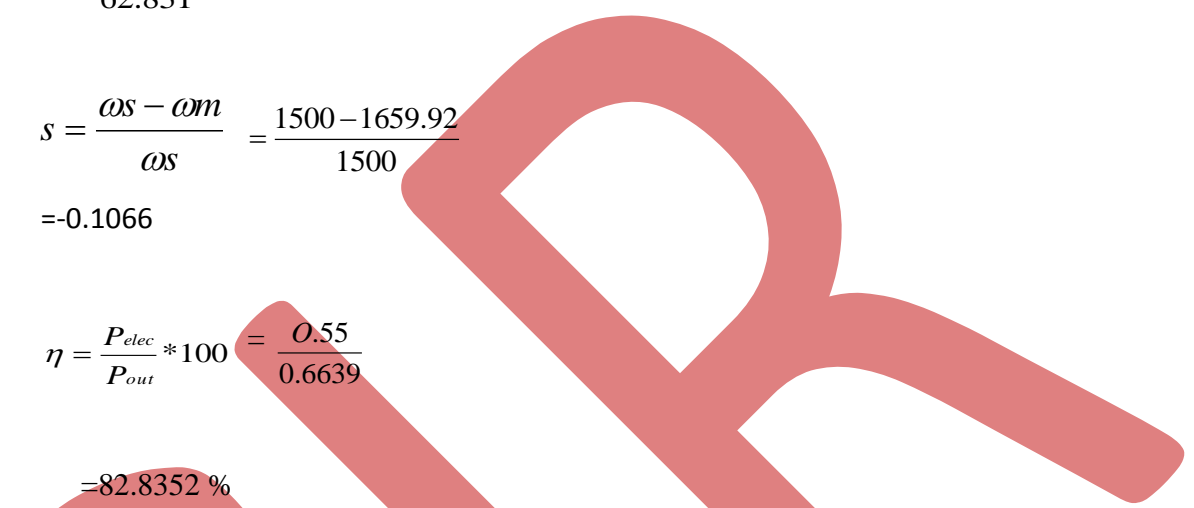

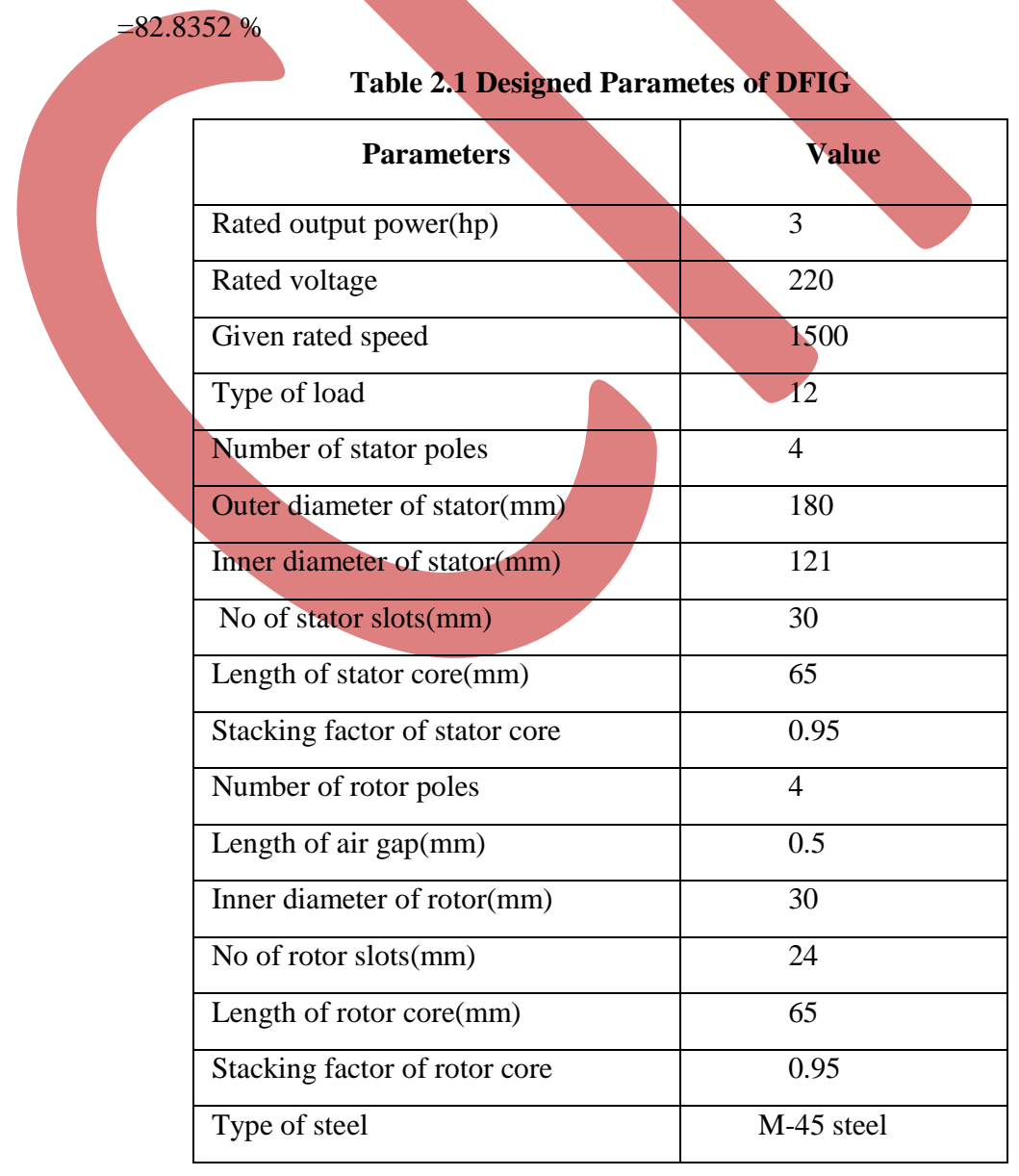




\subsection{FINITE ELEMENT ANALYSIS}

FEA consists of a computer model of a material or design that is stressed and analyzed for specific results. It is used in new product design, and existing product refinement. A company is able to verify a proposed design will be able to perform to the client's specifications prior to manufacturing or construction. Modifying an existing product or structure is utilized to qualify the product or structure for a new service condition. In case of structural failure, FEA may be used to help determine the design modifications to meet the new condition.

There are generally two types of analysis that are used in industry: 2-D modeling, and 3-D modeling. While 2-D modeling conserves simplicity and allows the analysis to be run on a relatively normal computer, it tends to yield less accurate results. 3-D modeling, however, produces more accurate results while sacrificing the ability to run on all but the fastest computers effectively. Within each of these modeling schemes, the programmer can insert numerous algorithms (functions) which may make the system behave linearly or non-linearly. Linear systems are far less complex and generally do not take into account plastic deformation. Non-linear systems do account for plastic deformation, and many also are capable of testing a material all the way to fracture.

FEA uses a complex system of points called nodes which make a grid called a mesh (Figure 2). This mesh is programmed to contain the material and structural properties which define how the structure will react to certain loading conditions. Nodes are assigned at a certain density throughout the material depending on the anticipated stress levels of a particular area. Regions which will receive large amounts of stress usually have a higher node density than those which experience little or no stress. Points of interest may consist of: fracture point of previously tested material, fillets, corners, complex detail, and high stress areas. The mesh acts like a spider web in that from each node, there extends a mesh element to each of the adjacent nodes. This web of vectors is what carries the material properties to the object, creating many elements

\subsection{RESULTS}

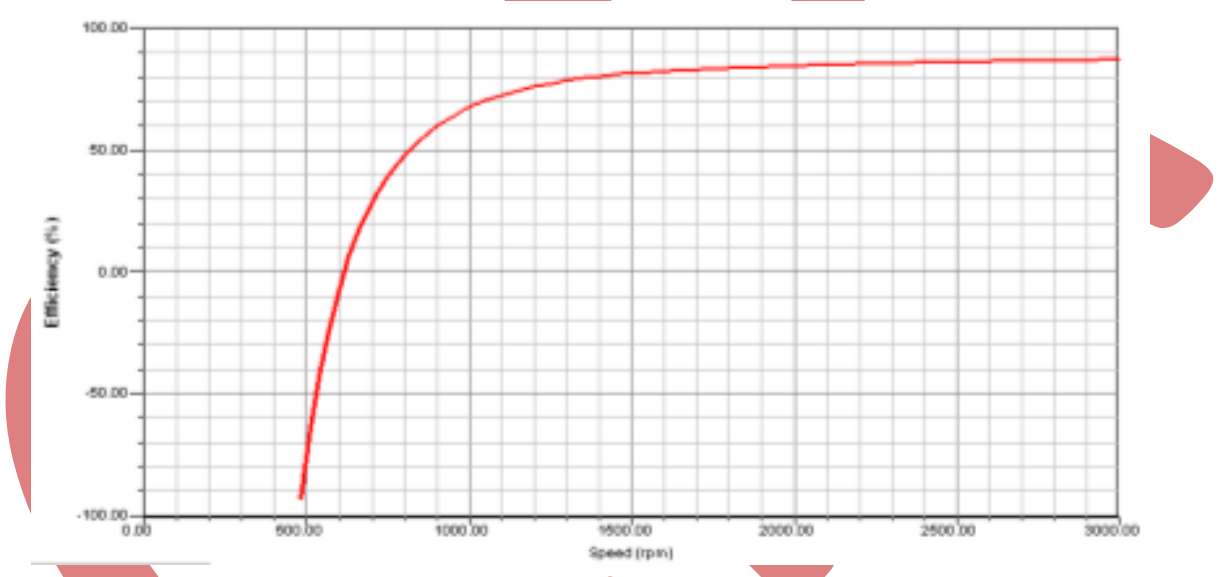

Fig 2.4.1 Speed Vs Efficiency

The Fig 2.4.1 shows the waveform of Speed Vs Efficiency. It shows that up to $500 \mathrm{rpm}$ the efficiency increases slowly and after reaching $500 \mathrm{rpm}$ it suddenly increases and reaches up to $82.83 \%$.

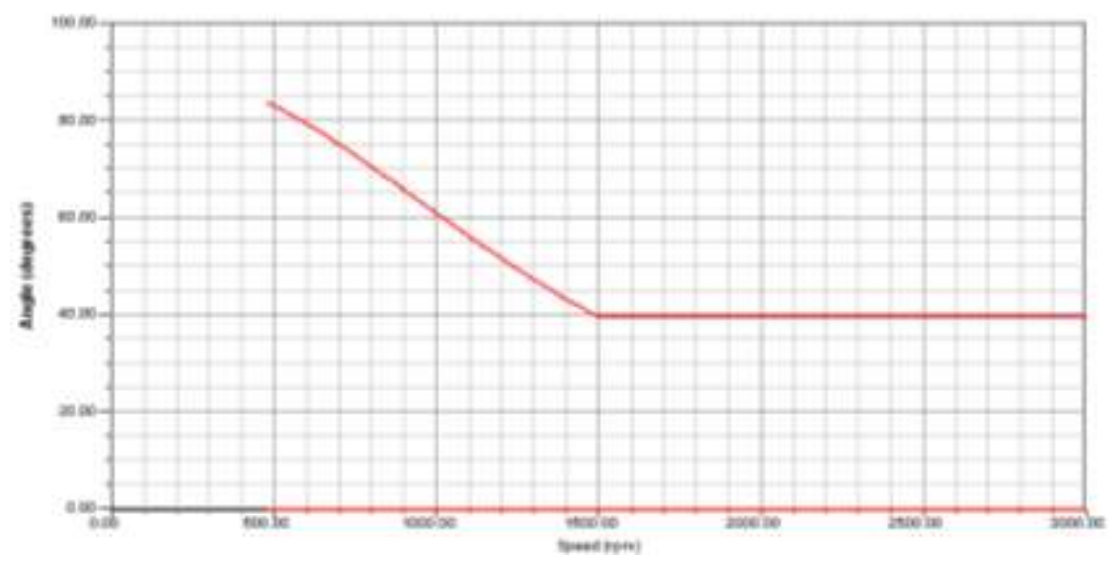

Fig 2.4.2 Speed Vs Angle

The Fig 2.4.2 describes about the Angle Vs Speed characteristics. When the speed is about $500 \mathrm{rpm}$ the angle is at 50 degree. Then the angle decreases with increase in speed from $500 \mathrm{rpm}$. Once $1500 \mathrm{rpm}$ speed is achieved the angle reaches 40 degree and remains get constant at that point. 


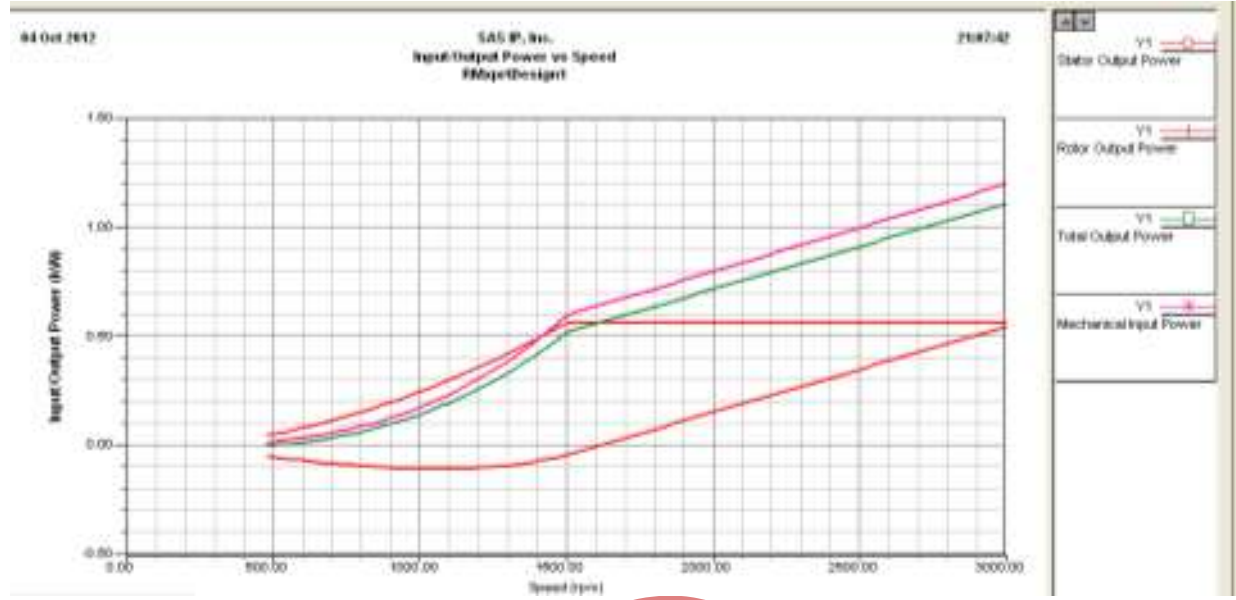

Fig 2.4.3 Speed Vs Input-Output Power

The Fig2.4.3 shows that the speed get increases according to the input power. The input power and the speed increases rapidly.

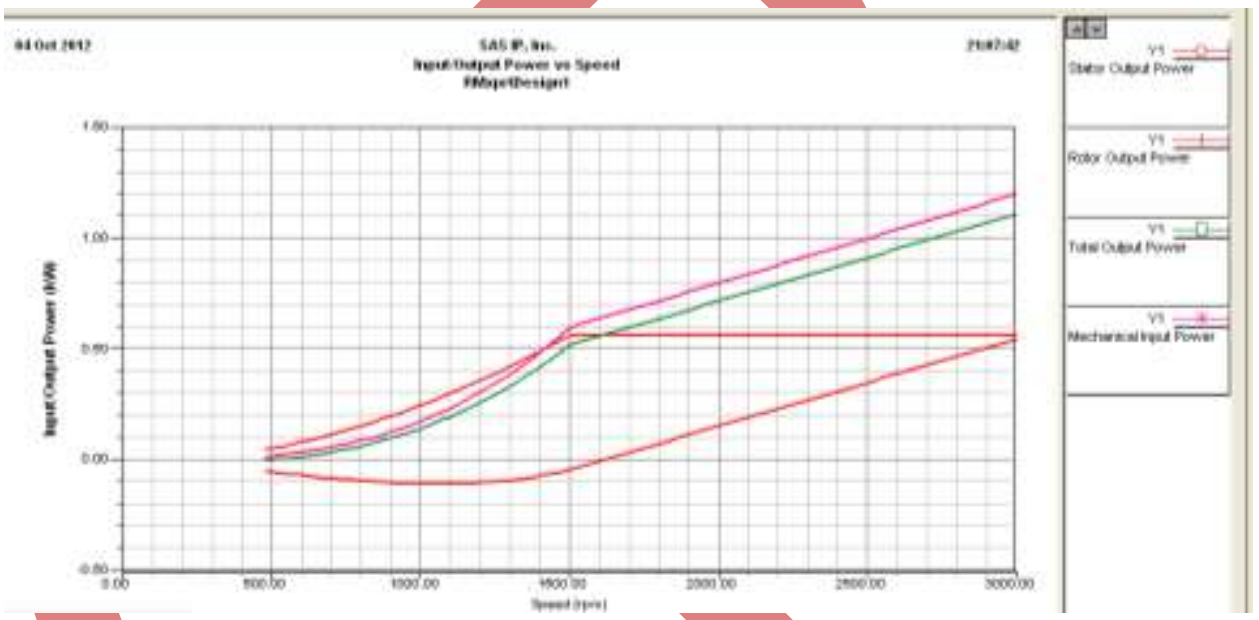

Fig 2.4.4 Speed Vs Input-Output Power

The Fig2.4.4 shows that the speed get increases according to the input power. The input power and the speed increases rapidly.

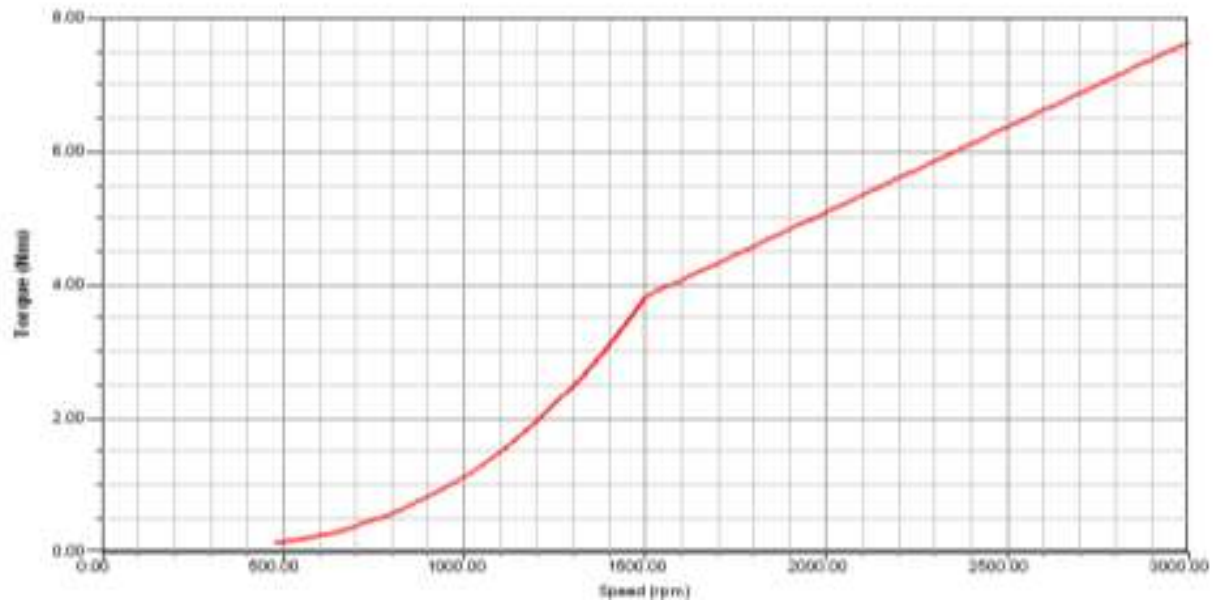

Fig 2.4.5 Torque Vs Speed

This Fig 2.4.5 shows the waveform of Torque Vs Speed. In this fig the torque is zero up to $500 \mathrm{rpm}$ speed and it increases with increasing the speed above $500 \mathrm{rpm}$ and finally it reaches $7.5 \mathrm{Nm}$ at $3000 \mathrm{rpm}$ speed. 


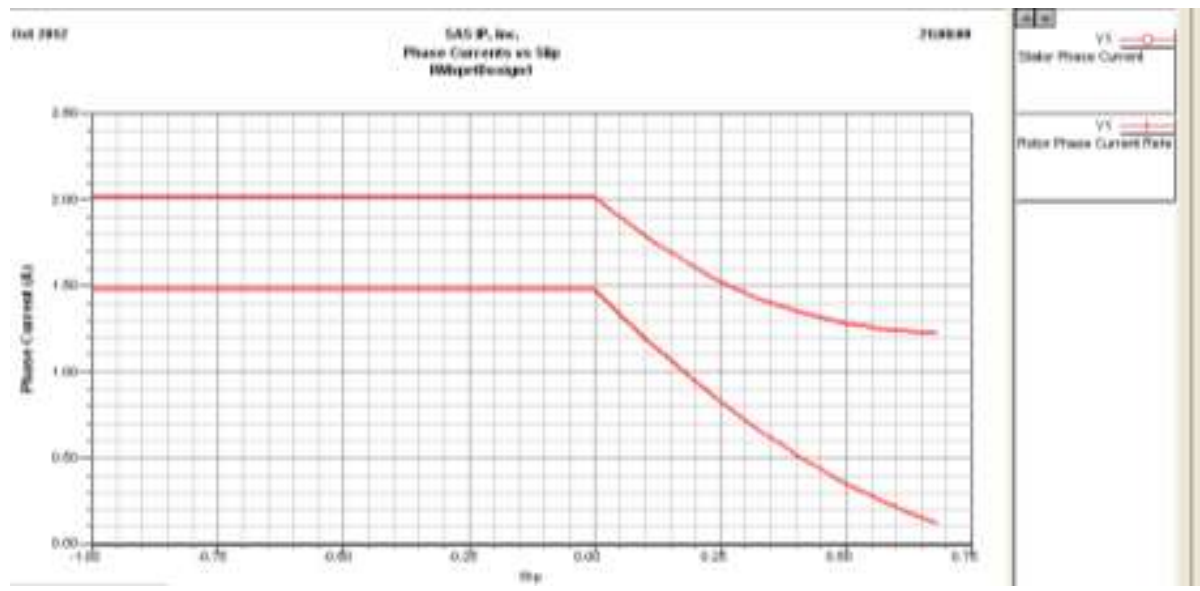

Fig 2.4.6 Slip Vs Phase Current

The Fig 2.4.6 that shows about the waveform of Slip Vs Phase Current. When the slip is at zero the current is 2 A. Then when the slip that get increase the current that decreases and reach the point to $0.10 \mathrm{~A}$. When the $2 \mathrm{~A}$ current is given the slip is zero and then by increasing the slip the current that decreases

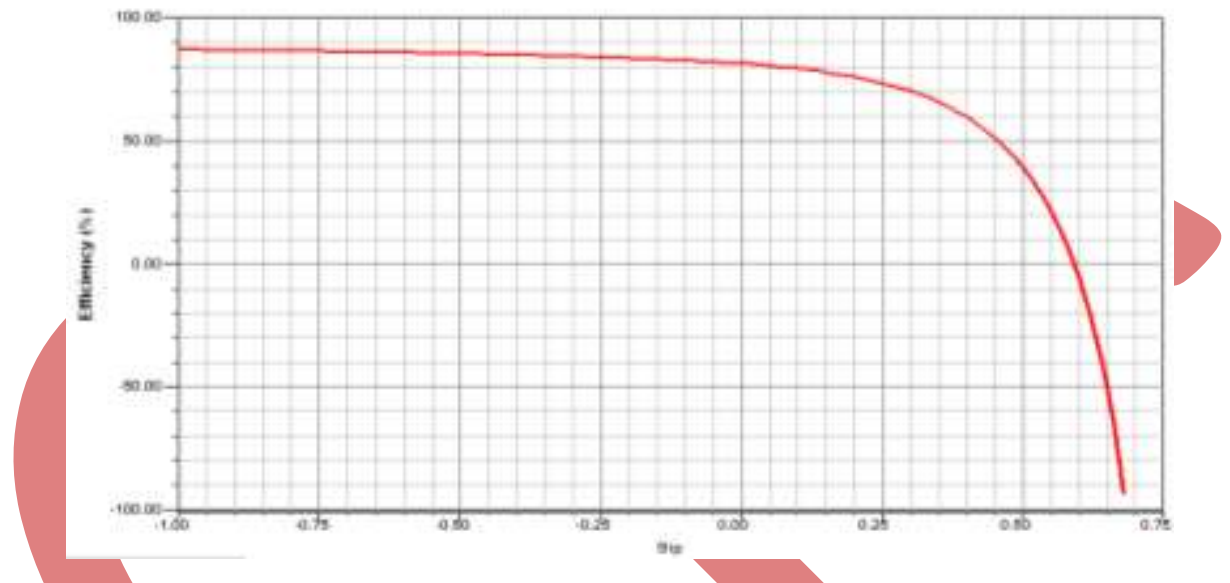

Fig2.4.7 Slip Vs Efficiency

The Fig2.4.7 shows about the waveform of Slip Vs Efficiency. The efficiency is $82 \%$ when the slip at the point from -1 to 0 . Then the slip increases with decrease in efficiency and reaches the point at $1.20 \mathrm{~A}$.

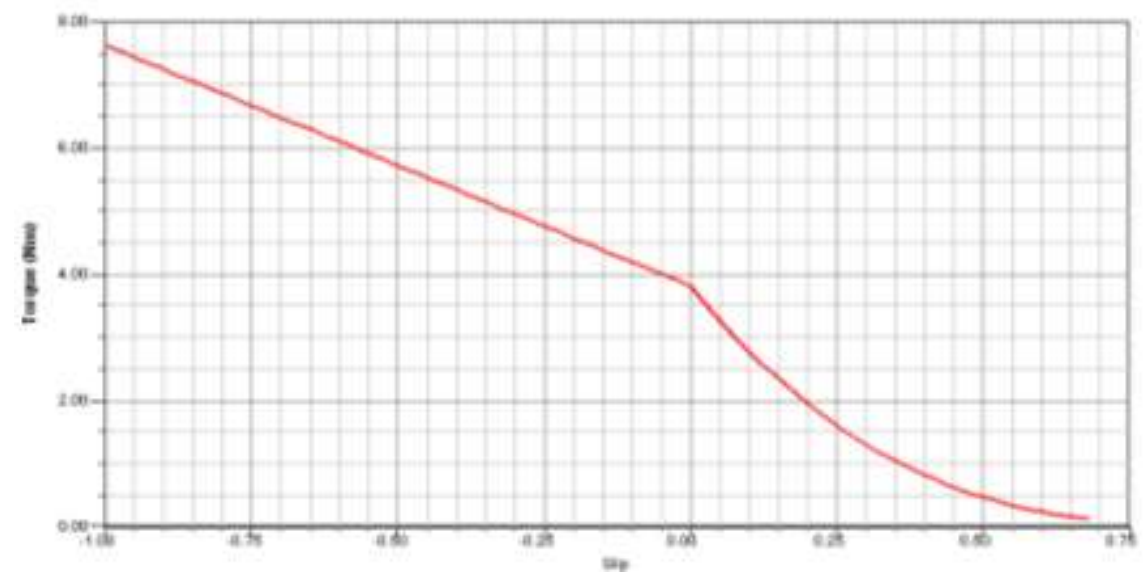

Fig 2.4.8 Torque Vs Slip

The Fig 2.4.8 that shows about the waveform of Torque Vs Slip. In this the torque is $8 \mathrm{Nm}$ when the slip at -1.0. Then by increasing the slip the torque that decreases and reaches the point 0 . 


\section{ANALYSIS OF THE SWITCHED RELUCTANCE GENERATOR}

Switched Reluctance Machines (SRM) can work as motor or as generators just by changing their switching angles. SRG has a mechanical input and an electrical input. Its output is the electrical power supplied to the load.

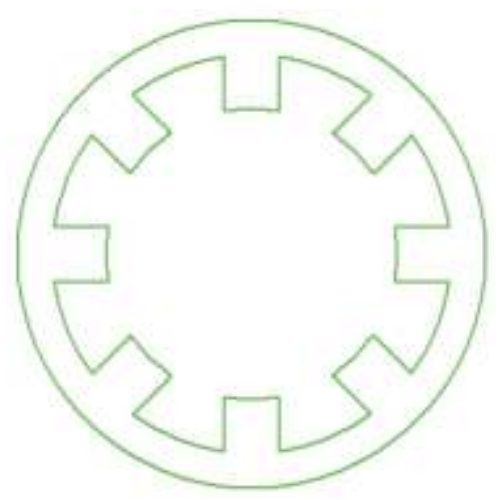

Fig 3.1 Stator of SRG
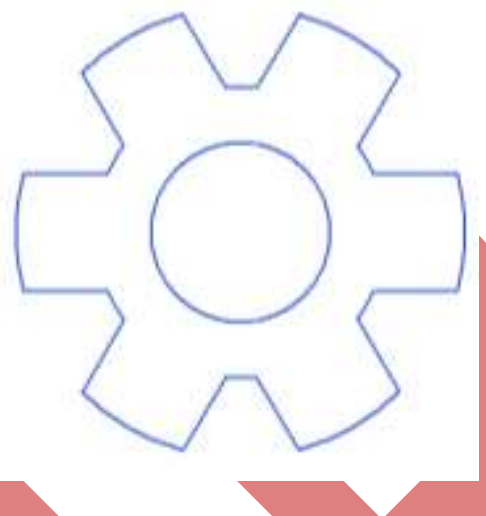

Fig 3.2 Rotor of SRG

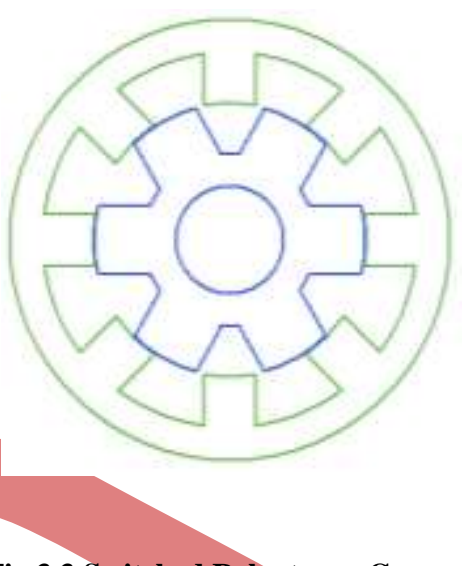

Fig 3.3 Switched Reluctance Generator

The voltage equation for a phase of $8 / 6$ SRG is

$$
\begin{aligned}
& X^{\prime}=R^{\prime} Y^{\prime}+\frac{d \theta}{d t}\left(L^{\prime} \frac{d Y^{\prime}}{d \theta}+L^{\prime \prime} \frac{d Y^{\prime \prime}}{d \theta}+L^{\prime \prime \prime} \frac{d Y^{\prime \prime \prime}}{d \theta}\right) \\
& +\frac{d \theta}{d t}\left(\frac{\partial L^{\prime}}{\partial \theta} Y^{\prime}+\frac{\partial L^{\prime \prime}}{\partial \theta} Y^{\prime \prime}+\frac{\partial L^{\prime \prime \prime}}{\partial \theta} Y^{\prime \prime \prime}\right)
\end{aligned}
$$

Where,

$X^{\prime}$ phase 'a' winding voltage (volts)

$Y^{\prime}, Y^{\prime \prime}, Y^{\prime \prime \prime}-$ phase currents (amps)

$R^{\prime}$ resistance of the phase a winding

$L^{\prime} \quad$ self ind uctance of phase 'a' (Henry)

$L$ ' self inductance among phase 'a' and 'b'(Henry)

$L^{\prime \prime \prime}$ self inductance among phase 'a' and 'c'(Henry)

$\theta$ rotor angular position (deg)

The induced electromotive force $\mathrm{f}$ is given by $z=\frac{d \theta}{d t}\left(\frac{\partial L^{\prime}}{\partial \theta} i^{\prime}+\frac{\partial L^{\prime \prime}}{\partial \theta} i^{\prime \prime}+\frac{\partial L^{\prime \prime \prime}}{\partial \theta} i^{\prime \prime \prime}\right)$

The supply is applied to the stator winding. When the back emf is positive electric power is converted to mechanical power and the machine works as motor. When the back emf is negative, it increases the current converting mechanical power into electrical power and the machine act as a generator. 
Council for Innovative Research www.cirworld.com
International Journal of Computers \& Technology Volume 4 No. 2, March-April, 2013, ISSN 2277-3061

\subsection{DESIGN CALCULATION}

The torque equation of SRG is given as

$$
T=\frac{P}{\omega}
$$

Where,

$$
\begin{aligned}
& P \text { - Power } \\
& \omega^{\prime} \text { - Angular speed }
\end{aligned}
$$

The angular speed of the SRG is given as

$$
\omega^{\prime}=\frac{2 * \pi * N}{60}
$$

Where,

$\mathrm{N}$ - Speed in rpm

$\omega^{\prime}$ - Angular speed ( rpm)

The stator outer diameter $D_{o}$ is given as

$D_{o}=2 * r(\mathrm{~m})$

$r=\frac{L}{2 * \pi}$

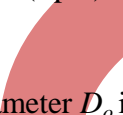

Where,

$\mathrm{D}_{0}$ - the outer diameter in meter

$r$ - the radius in meter

$L$ - stack length in meter

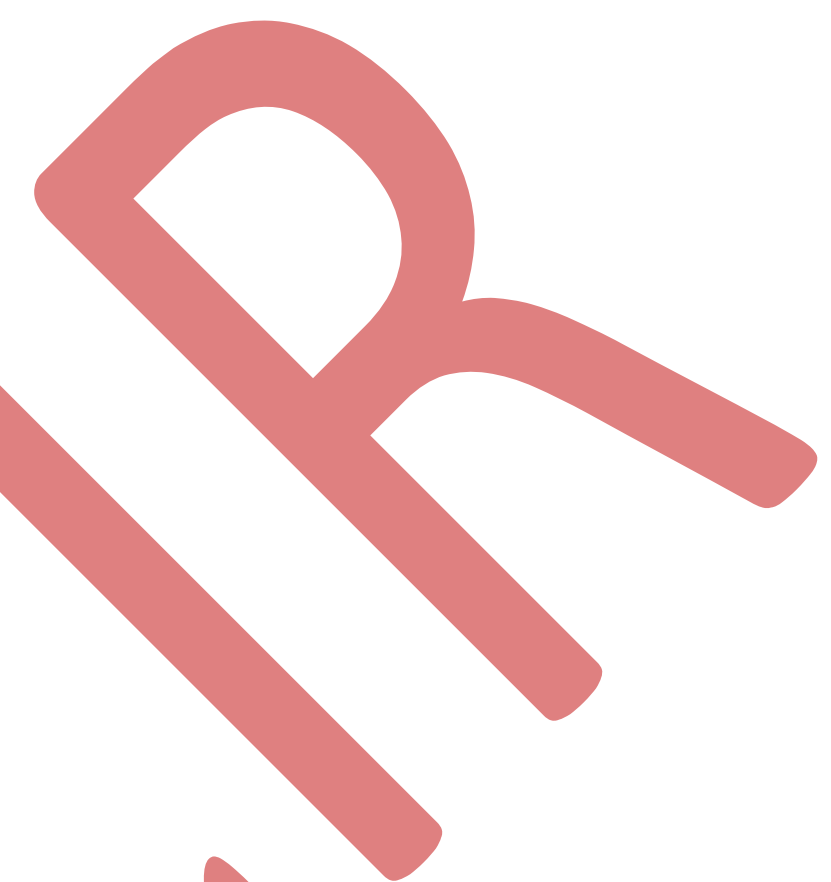

(4)

(5)

MMF drop equation of SRG is given as

$$
\zeta=2 *\left[H_{s} l_{s}+H_{g} \lg _{g} H_{g}+H_{r} l_{r}\right]+\frac{H_{s c} l_{s c}}{2}+\frac{H_{y} l_{y}}{2}
$$

Where,

$H_{s^{-}}$magnetic field induction of stator

Turns per phase of SRG is given as

$$
T_{p h}=\frac{\zeta}{i_{p}}
$$

Where,

$i_{p}$ - input power 
Council for Innovative Research www.cirworld.com

$\zeta$ - MMF drop equation of SRG

Aligned Inductance is given as

$L_{a}=\frac{T_{p h} * \phi}{i_{p}}$ (henry)

Where,

$T_{p h}$ - Turns per phase

$i_{p}$ - input power

$\phi$ - flux

Stator pole arc

$t_{s}=\left[\frac{D}{2}-g\right] * \beta_{s} * \frac{\pi}{180}$

Where,

$\beta_{s-\text { stator pole angle }}$

$D$ - the diameter

\subsection{ANAL YTICAL VALUE}

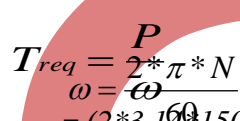

$=(2 * 3.1601500) / 60$

$=157.07 \mathrm{rpm}$

$T_{\text {req }}=960.972 / 157.07=6.118 \mathrm{~N} . \mathrm{m}$

Rotor diameter

$$
\text { Where } \begin{aligned}
D_{O} & =2 * r \\
r & =L /(2 * 3.14) \\
& =234.04 / 6.28=37.25 \mathrm{~mm} \\
D_{O} & =2 * 37.25 \quad=74.5 \mathrm{~mm}
\end{aligned}
$$

Bore diameter

$$
\begin{aligned}
D & =\left(D_{O} / 2\right)+82.75 \\
& =(74.5 / 2)+82.75 \\
& =120 \mathrm{~mm}
\end{aligned}
$$

Efficiency

$$
\eta=\frac{P_{\text {out }}}{P_{\text {in }}} 100=\frac{549.952}{960.972} * 100=57.2287 \%
$$


Table 3.1 Parameters of SRG

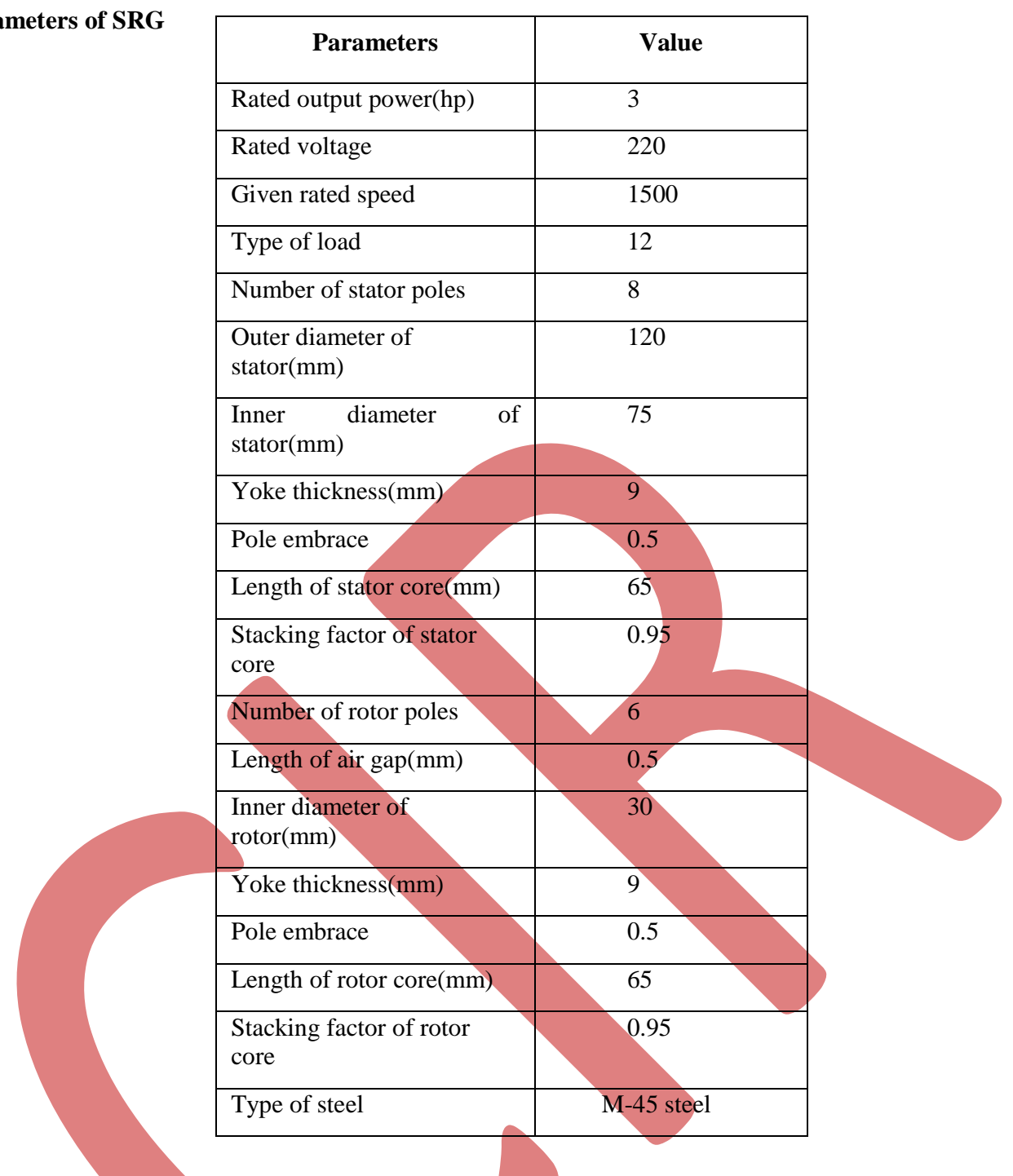

\subsection{FINITE ELEMENT ANALYSIS}

FEA consists of a computer model of a material or design that is stressed and analyzed for specific results. It is used in new product design, and existing product refinement. A company is able to verify a proposed design will be able to perform to the client's specifications prior to manufacturing or construction. Modifying an existing product or structure is utilized to qualify the product or structure for a new service condition. In case of structural failure, FEA may be used to help determine the design modifications to meet the new condition.

There are generally two types of analysis that are used in industry: 2-D modeling, and 3-D modeling. While 2-D modeling conserves simplicity and allows the analysis to be run on a relatively normal computer, it tends to yield less accurate results. 3-D modeling, however, produces more accurate results while sacrificing the ability to run on all but the fastest computers effectively. Within each of these modeling schemes, the programmer can insert numerous algorithms (functions) which may make the system behave linearly or non-linearly. Linear systems are far less complex and generally do not take into account plastic deformation. Nonlinear systems do account for plastic deformation, and many also are capable of testing a material all the way to fracture.

FEA uses a complex system of points called nodes which make a grid called a mesh (Figure 2). This mesh is programmed to contain the material and structural properties which define how the structure will react to certain loading conditions. Nodes are assigned at a certain density throughout the material depending on the anticipated stress levels of a particular area. Regions which will receive large amounts of stress usually have a higher node density than those which experience little or no stress. Points of interest may consist of: fracture point of previously tested material, fillets, corners, complex detail, and high stress areas. The mesh acts like a spider web in that from each node, there extends a mesh element to each of the adjacent nodes. This web of vectors is what carries the material properties to the object, creating many elements 


\subsection{RESULTS}

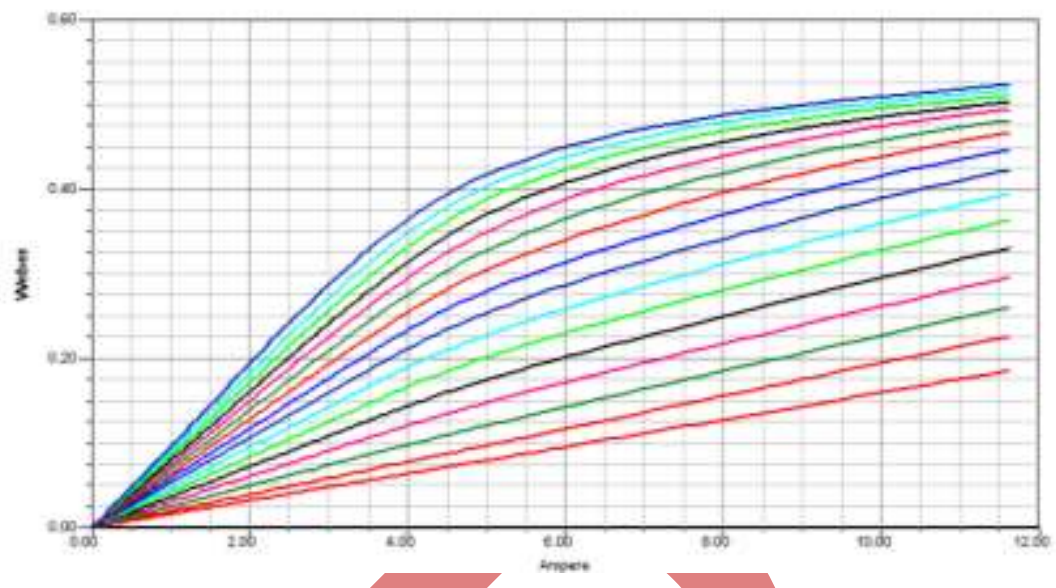

Fig 3.5.1 Fhux linkage vs Current

The Fig3.5.1 that shows the graph of flux linkage and current. In that at varying current the flux linkage that get increases at the certain point the flux linkage that get slowly increases.

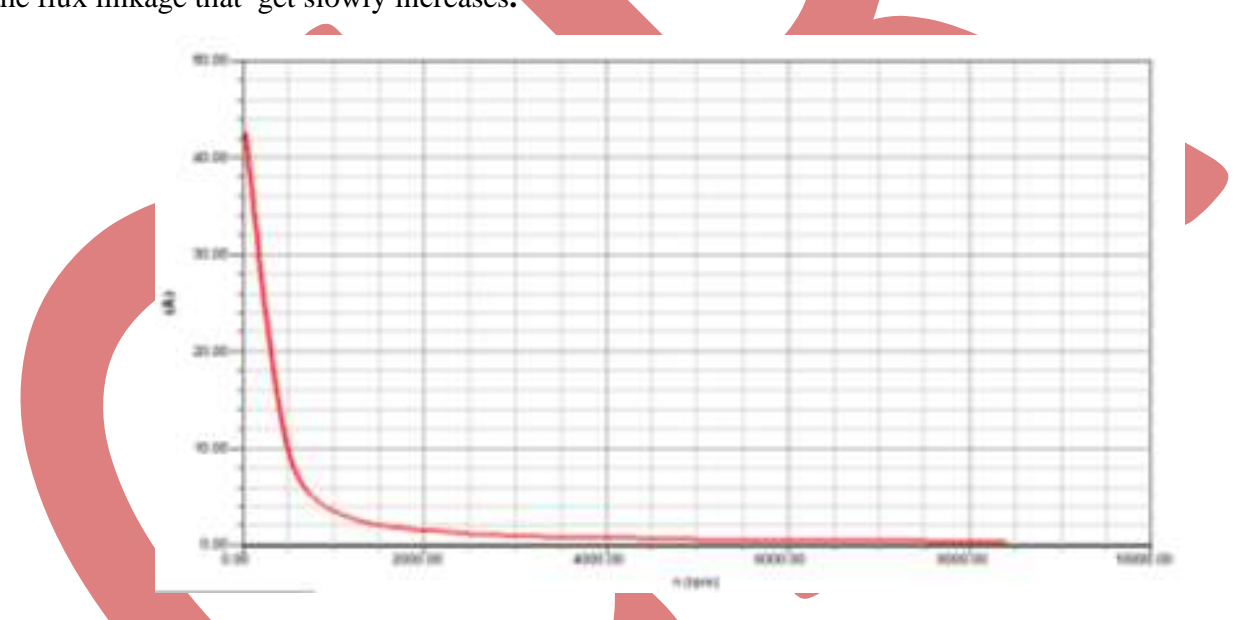

Fig3.5.2 Generated Current for different Speed

The Fig 3.5.2 that shows the graph of current and speed. In this the graph that shows at starting point the current is very high and then the speed that get increases and the current that decreases to the very low value.

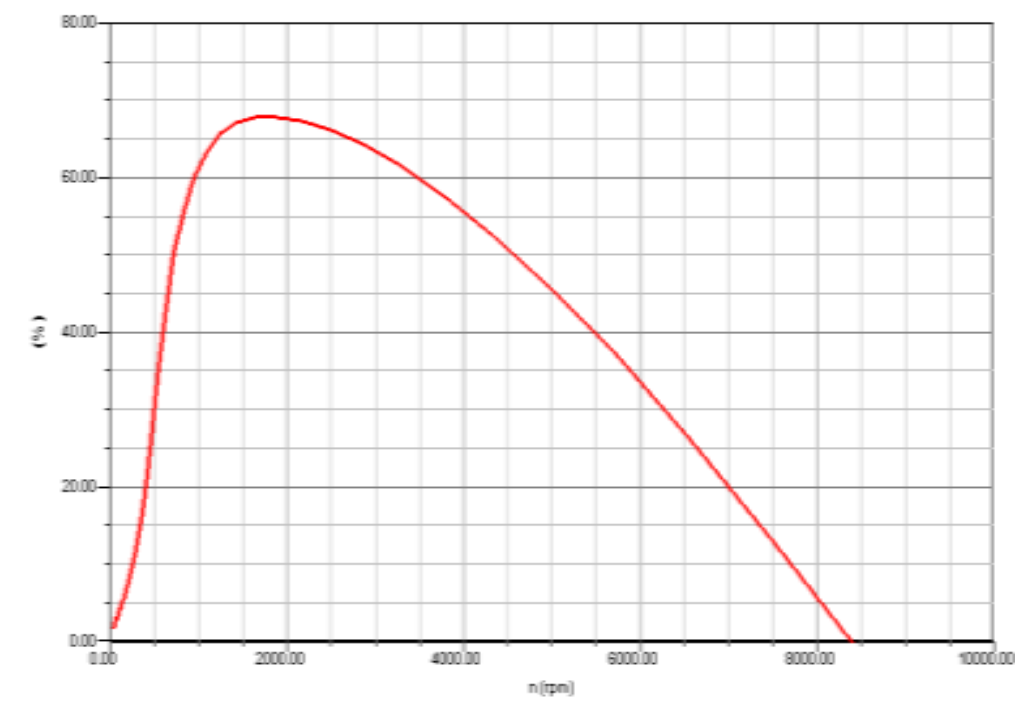

Fig 3.5.3 Efficiency vs Speed 
The Fig 3.5.3 that shows the graph of efficiency and speed. In this the efficiency that get increases suddenly and then speed increase and then gradually the efficiency that get decreases.

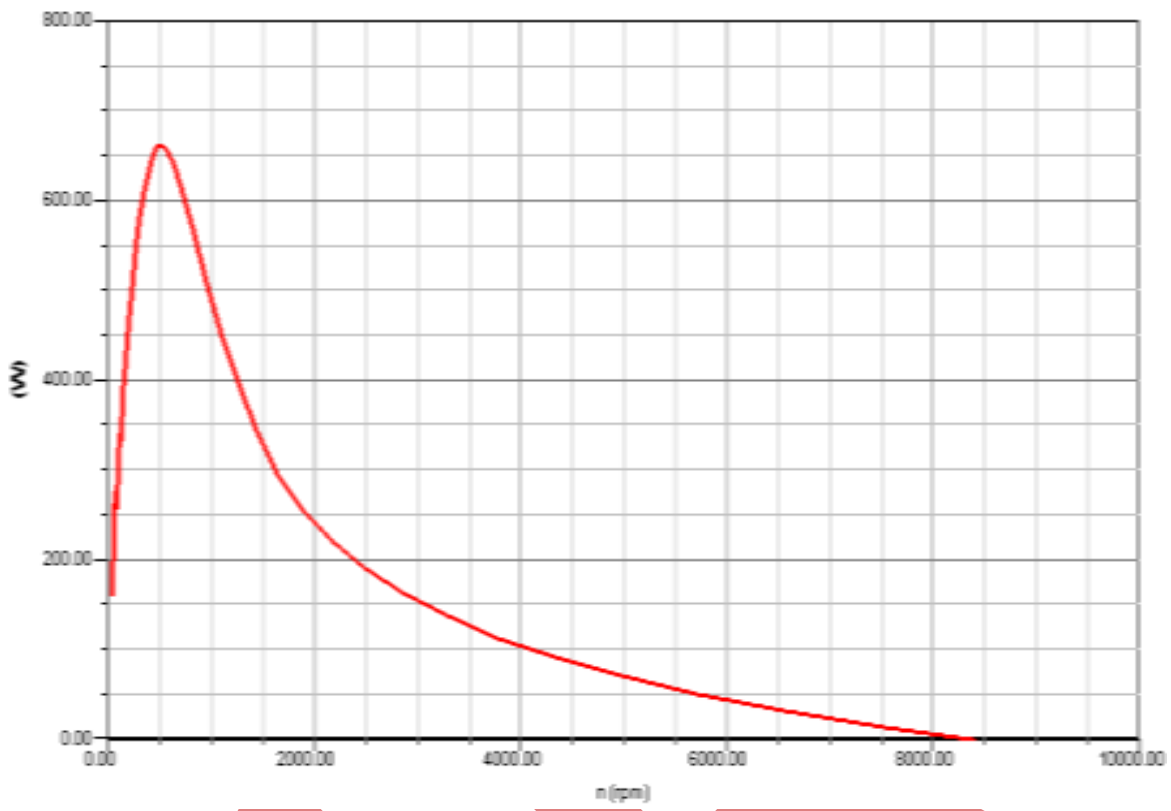

Fig 3.5.4 output power vs angular speed

The Fig3.5.4 that shows the output power and the angular speed. At the starting point the output power increases and then it decreases suddenly but the speed that increases gradually.

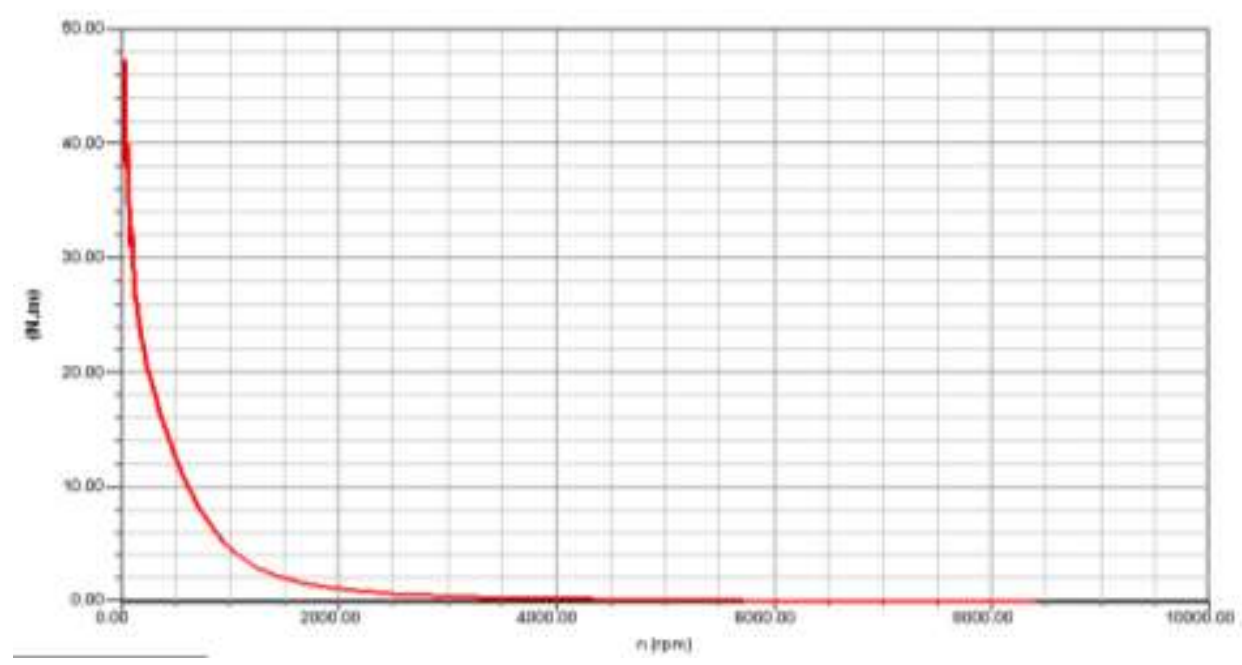

Fig 3.5.5 Torques vs Speed

The Fig3.5.5 that shows the graoh of torque vs speed. In this graph that explains at starting point the torque is very high and then it decreases the speed that get increases gradually.

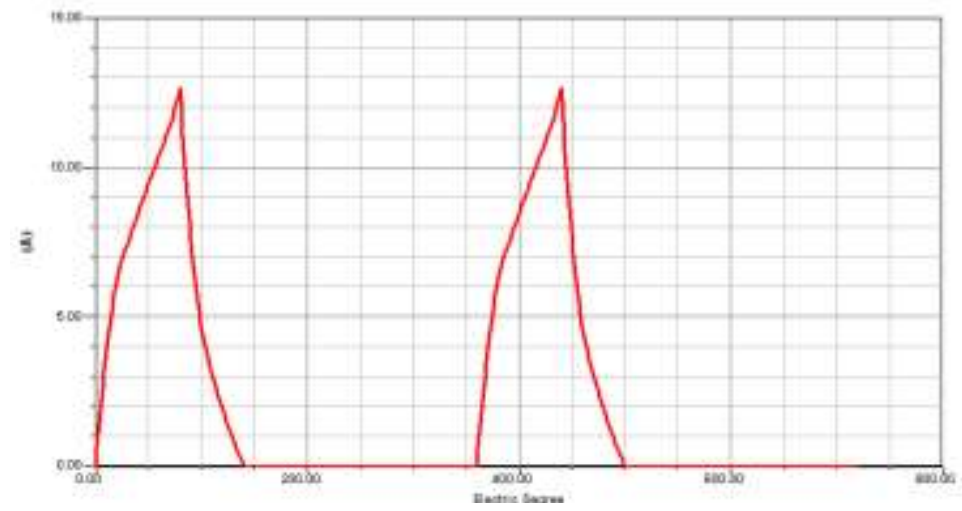


Council for Innovative Research www.cirworld.com
International Journal of Computers \& Technology

Volume 4 No. 2, March-April, 2013, ISSN 2277-3061

Fig 3.5.6 Current vs rotor position

The Fig3.5.6 that shows the graph of current vs rotor position. This graph that shows the the current increases to the certain point and decreases to zero then the rotor that shows the position.

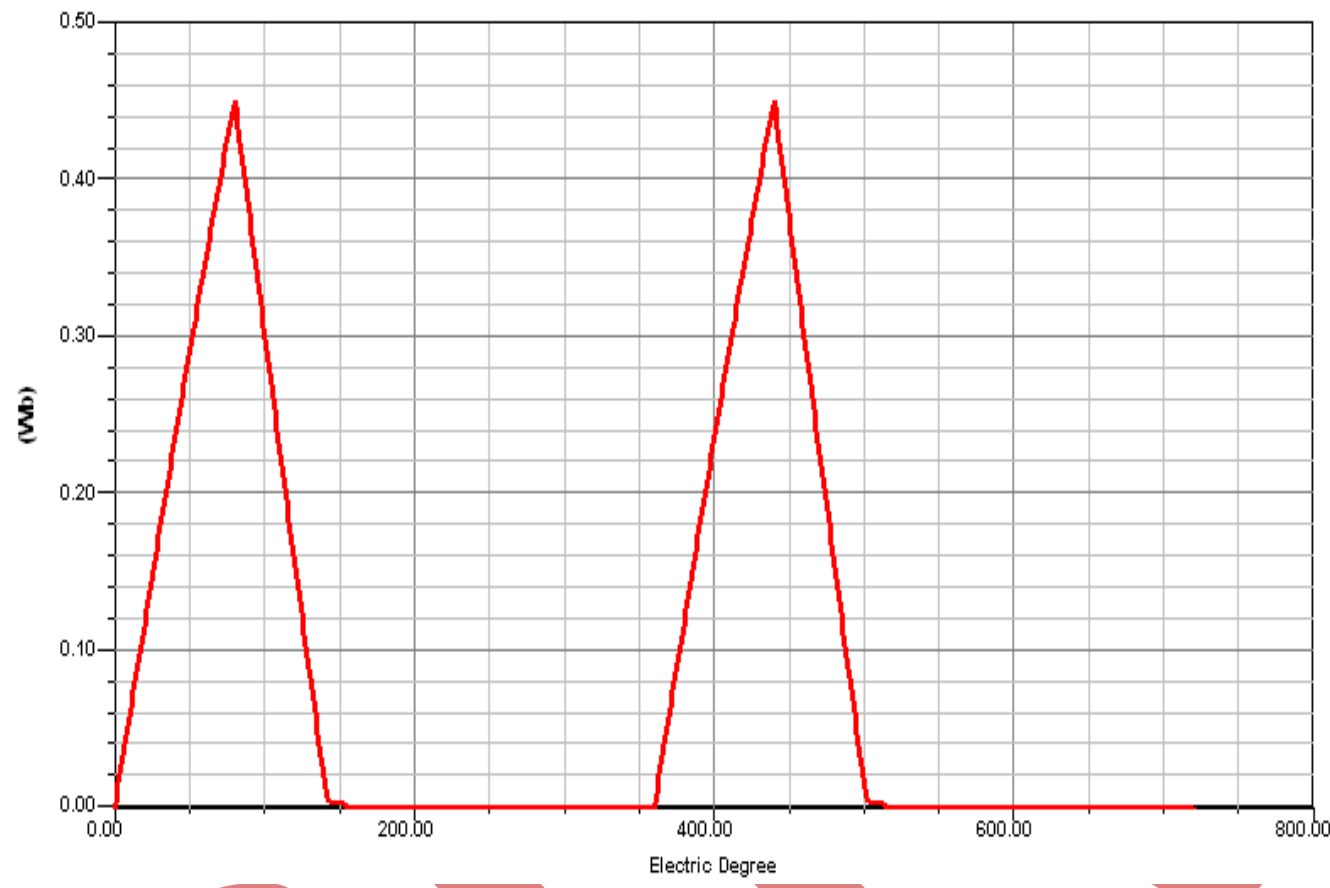

Fig 3.5.7 Flux vs rotor position

The Fig3 5.7 that shows the graph of flux vs rotor position. Thi graph that clearly explains about the rotor positon and then flux for the different rotor position.

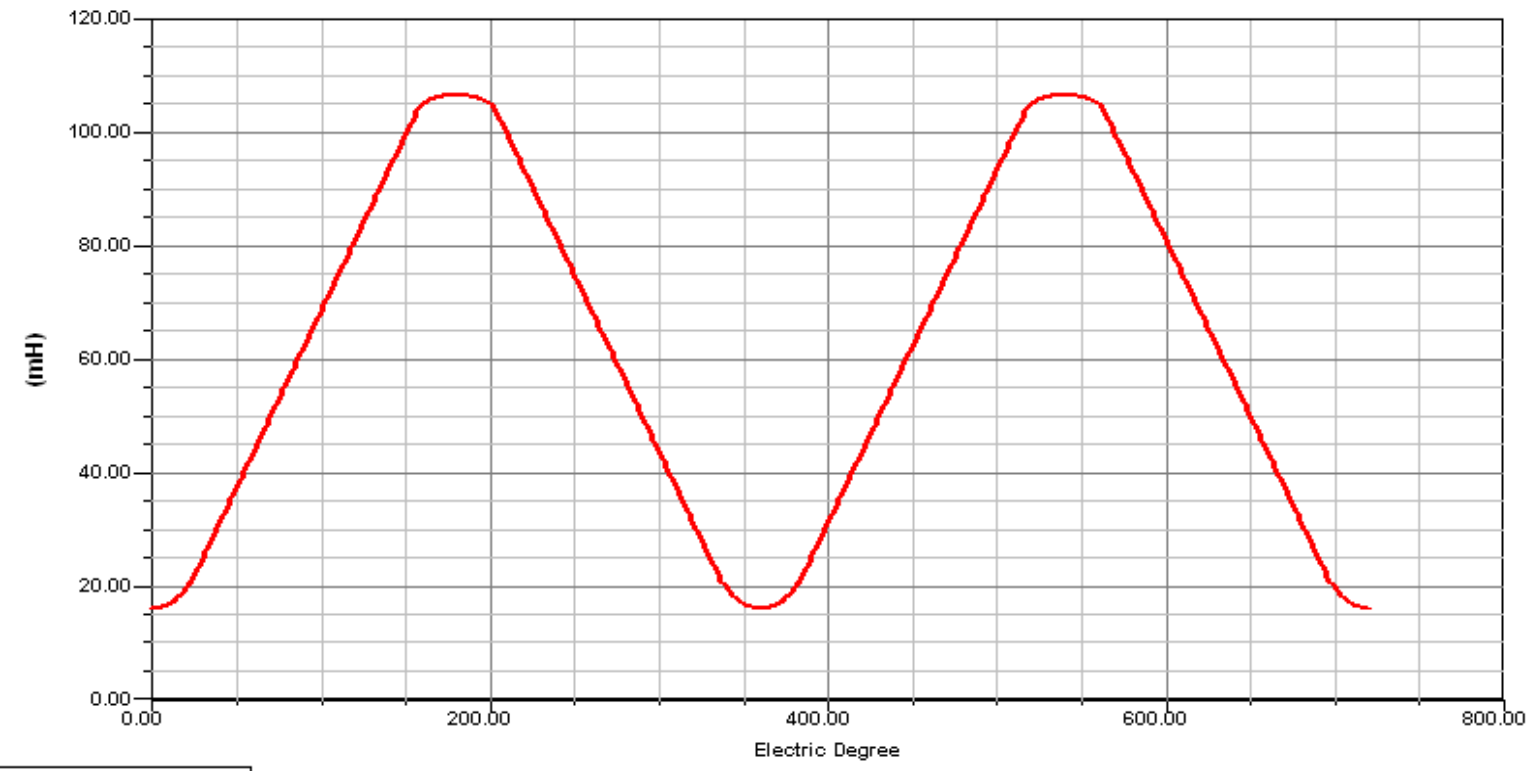

Fig 3.5.8 Inductance vs rotor position

The Fig 3.5.8 that shows the graph of inductance vs otor position. The gaph that shows the inductance value for the different rotor position. 


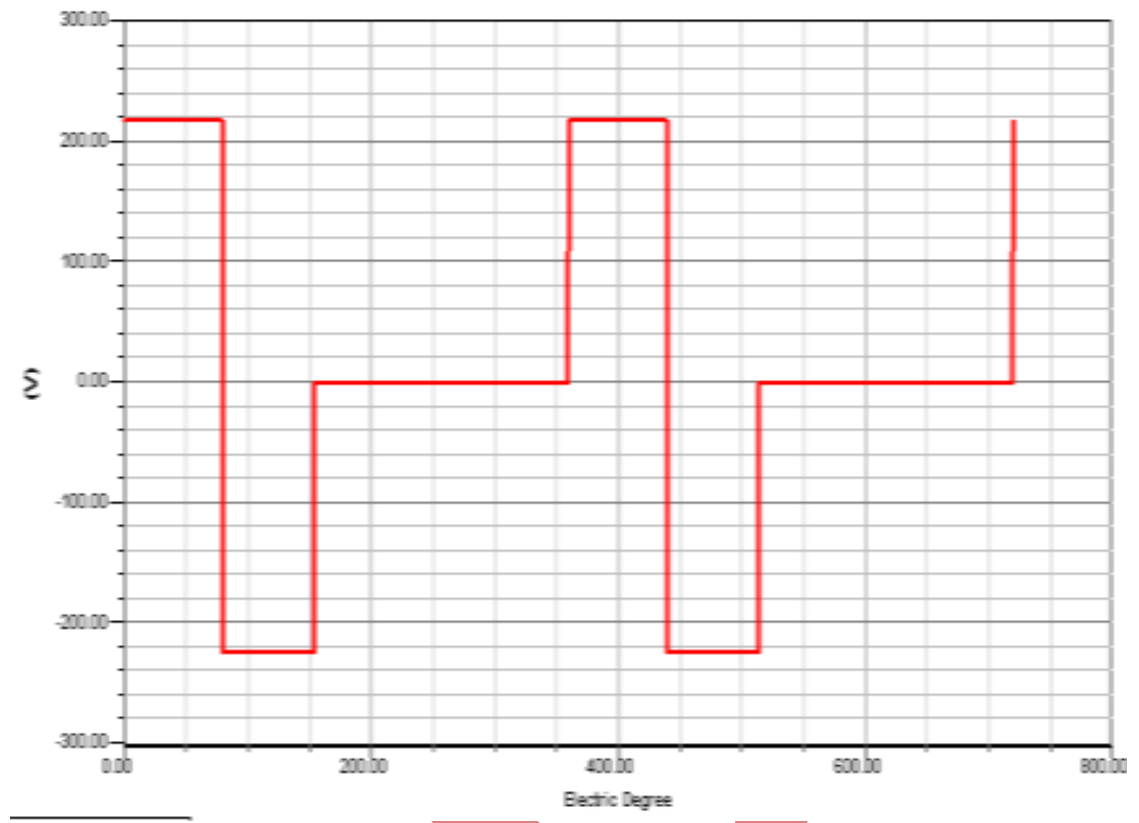

Fig 3.5.9 Voltage vs Electric degree

The Fig3.5.9 that shows about the graph of voltage vs electric degree. The graph that clearly explains about the voltage for the electric degree.

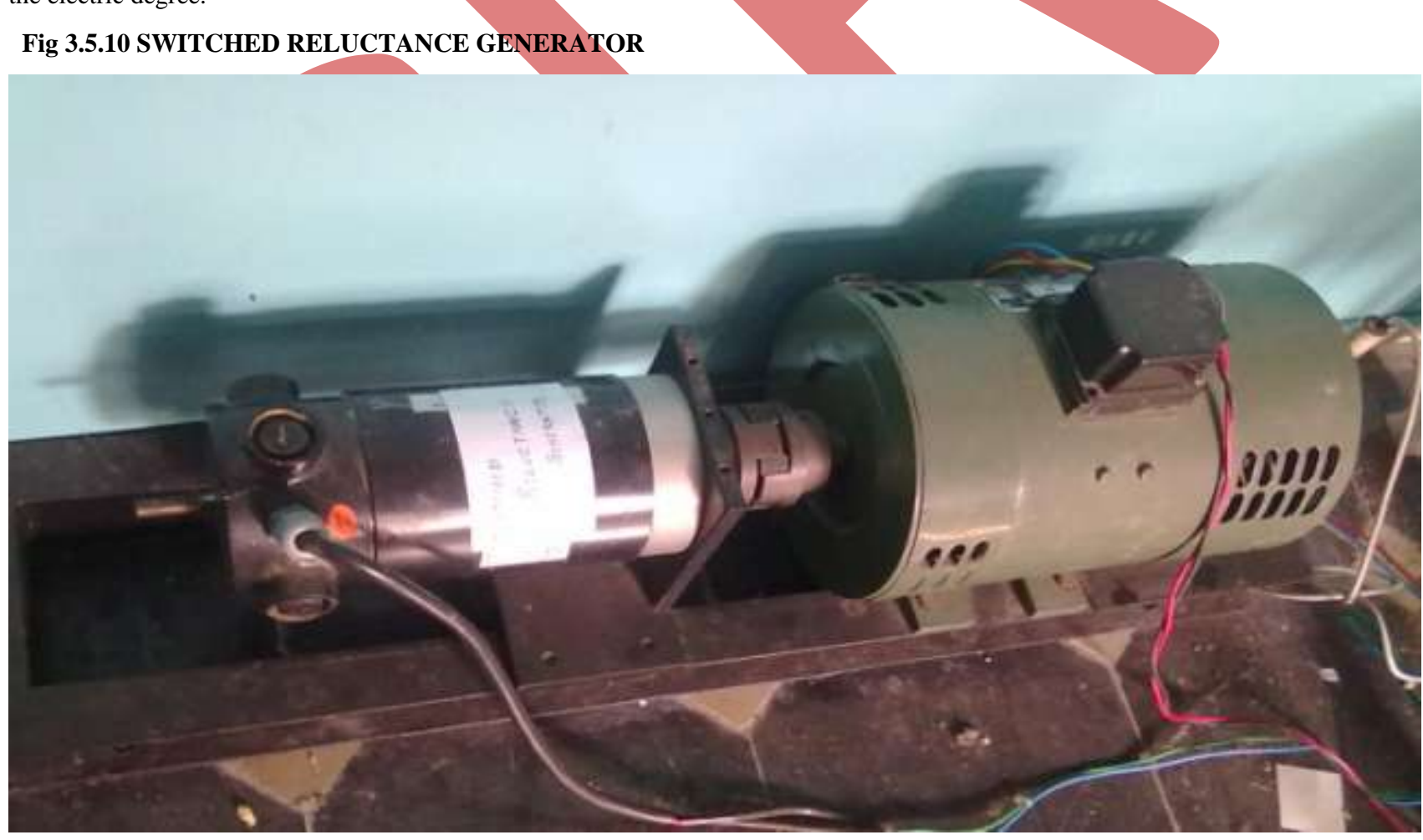

Table 3.2 Analytical Vs FEA

\begin{tabular}{|l|l|l|l|}
\hline \multicolumn{1}{|c|}{ Parameters } & Analytical & FEA & $\begin{array}{c}\text { Experimental } \\
\text { value }\end{array}$ \\
\hline Toque & 6.118 & 6.089 & 7.217 \\
\hline Efficiency & 56.2287 & 57.228 & 59.212 \\
\hline
\end{tabular}




\subsection{CONCLUSION}

The main advantages of renewable are available, clean, low cost and continuous energy. The reasons for choosing induction generator in wind energy system are that its very reliable tends to be comparatively inexpensive, light weight and low maintenance. The generator also has some mechanical properties which are useful for wind turbines. So, the SRG is the most common generator in wind energy system applications due to its simplicity and ruggedness. The used formula to calculate the minimum values required for Switched Reluctance Generator is simple. The formula which used here gives typical results of the given parameters. This analysis and the waveforms are done by using the magnet software.

\section{REFERENCES}

[1] A.Fleury, D.A.Andrade, F.S.Silva, J.L.Domingos.,"Switched Reluctance Generator Behaviour Under Different Condition”, in IEEE International symposium on industrial electronics, ISIE'07 records. 2007.

[2] R.Cardenas, R.Pena, M.Perez, G.Asher, J.Clare, O.Wheeler, 'Control System for grid generation of switched reluctance generator driven by variable speed wind turbine,"in industrial electronic society, 2004. IECON 2004. $3^{\text {th }}$ Annual conference ofIEEE, vol.2,2-6 nov.2004,pp.1879-1884.

[3] H. Chen, "Implementation of a Three-Phase Switched Reluctance Generator System for Wind Power Applica-tions," 14th Symposium on Electromagnetic Launch Technology, Victoria, 2008, pp. 1-6. doi:10.1109/ELT.2008.104

[4] W. Carlin, A.S. Laxson, and E.B. Muljadi, "The History and State of the Art of Variable-Speed Wind Turbine Technology", technical report for National Renewable Energy Laboratory, Feb. 2001.

[5] T.J. Miller,Switched Reluctance Motors and Their Control. University of Glasgow, Scottland, 1993, pp. 51.

[6] I.Husain, A.Radun and J.Nairus, "Fault Analysis and Excitation Requirements for Switched Reluctance Generators," IEEE Trans. Energy Conversion, vol. 17, No.1, pp. 67-72, March. 2002.

[7] K. De Brabandere, J. Driesen and R. Belmans, "The Control of Switched Reluctance Drive and Their Use for Flywheel Energy Storage," unpublished.

[8] V. Nedic and T.A. Lipo, "Experimental Verification of Induced Voltage Self Excitation of a Switched Reluctance Generator," presented at the IEEE/IAS Conference Record, Rome, Italy, October, 2000, vol. 1, pp.51-56.

[9] D. Torrey, "Switched Reluctance Generators and Their Control," IEEE Trans. Industrial Electronics, vol. 49, No.1, pp. 3-14, Feb. 2002.

[10] O. Ichinokura, T. Kikuchi, K. Nakamura, T. Watanabe and H. Guo, "Dynamic Simulation Model of Switched Reluctance Generator," IEEE Trans. Magnetics, vol. 39, No.5, pp. 3253-3255, Sept. 2003

[11] R.Dubois, "Optimized Permanent Magnet Generato Toplogies for Direct- Drive Wind Turbines," Ph.D. dissertation, Technical University of Delft, Netherlands, 2004.

[12] T. Rovio, H. Vihriälä, L.Söderlund, J. Kriikka and M. Hyppönen, “Axial and Radial Flux Generators in Small-Scale Wind Power Production,"presented at the European Wind Energy Conference, Copenhagen, Denmark, July, 2001.

[13] G. Asker, "Analysis, Modeling and Simulation of Doubly Fed Induction Generator using Simulink/Matlab and Plecs," project work summer semester, 2004.

[14] C.Brune, R.Spée and A.Wallace, "Experimental Evaluation of a Variable-Speed, Doubly-Fed Wind-Power Generation System," IEEETrans. Industry Applications, vol. 30, No.3, pp. 648-655, May/June 1994.

[15] A. Petersson, “Analysis, Modeling and Control of Doubly-Fed Induction Generators for Wind Turbines," Ph.D. dissertation, Dept.Elect.PowerEng.,ChalmersUniv.ofTechnology,Göteborg, 